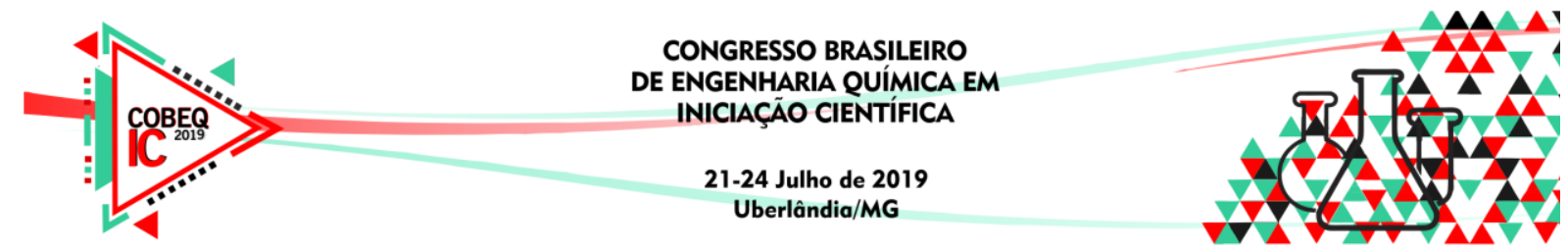

\title{
ESTUDO DA ADSORÇÃO DE AZUL DE METILENO UTILIZANDO CASCAS DE PEQUI (Caryocar brasiliensi Camb)
}

\author{
L. R. LOPES ${ }^{1}$; J. A. D. BARROSO ${ }^{1}$; R. N. CUNHA ${ }^{1}$ \\ ${ }^{1}$ Centro Universitário de Patos de Minas, Departamento de Engenharia Química \\ E-mail para contato: larissarl179@gmail.com
}

\begin{abstract}
RESUMO - O tratamento de efluentes industriais vem ganhando destaque, devido aos impactos ambientais que estes causam como os decorrentes da produção têxtil. Dentre as formas de tratamento, destaca-se a adsorção. A presente pesquisa teve como objetivo estudar o potencial adsorvente da casca do pequi sobre o corante azul de metileno. As cascas receberam tratamento ácido/básico. Os ensaios de adsorção foram realizados em batelada adotando-se PCC tendo-se como variáveis independentes o tempo e a massa de adsorvente e como parâmetro de resposta a porcentagem de remoção de corante. As condições ótimas de operação foram obtidas por meio de análises estatísticas. A casca de pequi favoreceu a adsorção do corante têxtil, o que contribui para a redução do seu descarte no meio ambiente.
\end{abstract}

\section{INTRODUÇÃO}

Os impactos decorrentes da produção têxtil envolvem a geração de efluentes que se caracterizam por apresentarem alta carga de compostos químicos orgânicos e presença significativa de corantes. Os corantes são os principais contaminantes desses efluentes, sendo estes compostos de difícil degradação e tóxicos ao meio ambiente. No Brasil, o setor têxtil utiliza anualmente 20 toneladas de corantes sendo que destes, $20 \%$ são descartados na forma de efluentes (DALLAGO et al., 2005 apud LUNARDI, 2014). Diante desse cenário, uma das principais dificuldades encontradas no tratamento de efluentes têxteis é a retirada da coloração da água.

Para reduzir os níveis de compostos tóxicos dos efluentes têxteis, as indústrias têm usado os processos de adsorção. O processo depende de fatores físicos como interação adsorvente/corante, área superficial do adsorvente, tamanho da partícula, temperatura, tempo de contato e $p H$ (NASCIMENTO et al., 2014). Dentre os adsorventes o carvão ativado se destaca no uso industrial, entretanto materiais alternativos vêm sendo utilizados em pesquisas científicas. De acordo com Gupta e Suhas (2009) apud Silva (2014), um adsorvente pode ser considerado de custo baixo, se necessitar de moderado processamento para ser utilizado; existir em elevada demanda na natureza ou mostrar-se como um subproduto industrial.

Conforme Silva et al. (2012) apud Amorim (2015), o pequi ou pequizeiro, cuja espécie conhecida como Caryocar Brasiliense é uma espécie encontrada em grande quantidade no cerrado brasileiro. Segundo o IBGE, em 2014, o pequi rendeu 14.589 mil reais para o Brasil, com uma produção de 19.241 toneladas, sendo Minas Gerais o maior produtor com 64,19\% 


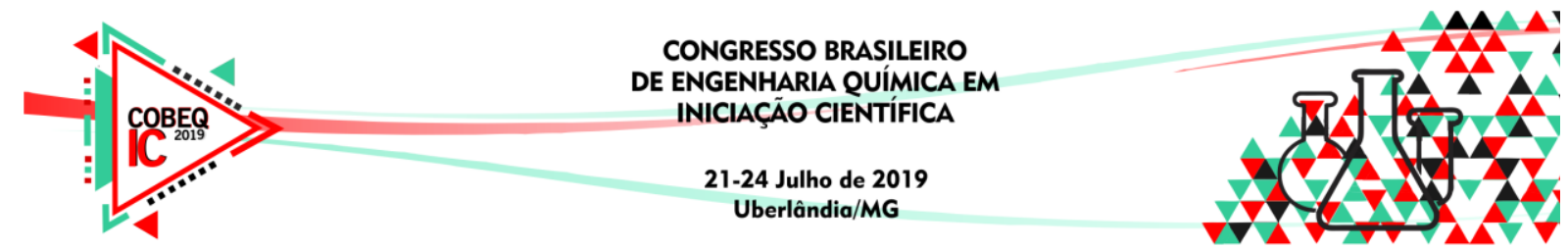

da produção. De acordo com Soares Júnior et al. (2009) o fruto é composto por $76 \%$ de casca e 21,6\% de pirênios. A casca do pequi já foi objeto de estudo na remoção de corantes no qual Olivério et al. (2015) a utilizou como adsorvente do corante vermelho de fenol em meio aquoso obtendo-se resultados satisfatórios.

O presente estudo teve como objetivo avaliar o potencial das cascas de pequi como adsorvente na adsorção do corante azul de metileno presente em soluções aquosas, utilizando para tanto, o regime batelada. Nesse sentido, a pesquisa visa contribuir na mitigação dos impactos ambientais sugerindo-se uma forma de reaproveitar as cascas do pequi bem como reduzindo os impactos gerados pelo azul de metileno.

\section{METODOLOGIA}

\subsection{O material-cascas de pequi}

As cascas de pequi foram coletadas em Cana Brava distrito de João Pinheiro - MG e levadas para o Laboratório de Engenharia Química do Centro Universitário de Patos de Minas. Os resíduos foram lavados com água destilada e secos em estufa com recirculação de ar até peso constante. O material seco foi triturado com o auxílio de um liquidificador industrial e peneirado em peneirador vibratório Bertel, sendo utilizada a fração -28+48 mesh (Tyler). Visando aumentar os sítios ativos, o material foi submetido ao tratamento ácido/base proposto por Rosas et al. (2016) utilizando soluções de $\mathrm{HCl}\left(0,1 \mathrm{~mol} . \mathrm{L}^{-1}\right)$ e $\mathrm{NaOH}(0,1$ mol. $\mathrm{L}^{-1}$ ) e lavado com água destilada até que a solução atingisse o $p \mathrm{H}$ neutro.

\subsection{Curva de calibração}

A construção da curva de calibração foi realizada em colorímetro CL-3003 Photometer por meio da leitura da absorbância no comprimento de onda de $660 \mathrm{~nm}$. As soluções aquosas de corante azul de metileno foram preparadas previamente nas concentrações de 0,1 a 22,4 mg. $L^{-1}$. Obteve-se para a curva de calibração o coeficiente de determinação $\left(R^{2}\right)$ de 0,9982 , indicativo de elevado ajuste aos dados experimentais.

\subsection{Ponto de carga zero}

Para determinação do $p \mathrm{H}_{\mathrm{PCZ}}$ foram adicionados $0,1 \mathrm{~g}$ do adsorvente em $25 \mathrm{~mL}$ de soluções de $\mathrm{KCl}\left(0,1 \mathrm{~mol}^{-1} \mathrm{~L}^{-1}\right)$ com $p \mathrm{H}$ variando de 1 a 14 . Tais $p \mathrm{Hs}$ foram ajustados com soluções de $\mathrm{HCl}$ e $\mathrm{NaOH}$. As misturas ficaram em contato por $24 \mathrm{~h}$ e, posteriormente, foram filtradas. $\mathrm{O}$ valor do $\mathrm{pH}$ no ponto de carga zero foi estimado a partir do gráfico da variação do $p \mathrm{H}\left(p \mathrm{H}_{\text {inicial }}-p \mathrm{H}_{\text {final }}\right)$ em função do $p \mathrm{H}_{\text {inicial }}$ (AMORIM, 2015).

\subsection{Ensaios de adsorção}

Os ensaios experimentais de adsorção foram conduzidos em erlenmeyers de $250 \mathrm{~mL}$ contendo massas distintas de adsorvente em $100 \mathrm{~mL}$ da solução do corante na concentração de 22,4 mg. $\mathrm{L}^{-1}$ e $p \mathrm{H}$ de 6,6. Os ensaios foram todos realizados em triplicata. Como variáveis independentes foram adotadas a massa de adsorvente e o tempo de contato, o qual foi 


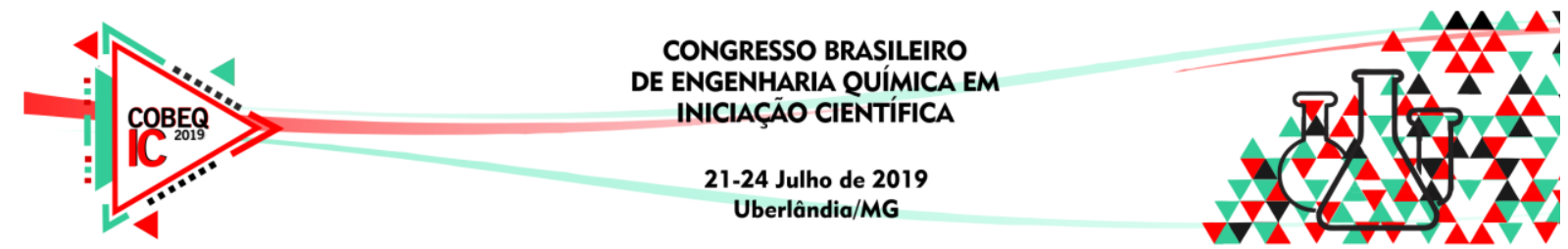

realizado em sistema batelada em shaker Quimis®. Os ensaios foram conduzidos por meio de planejamento composto central, com as variáveis codificadas descritas pela Tabela 1.

Tabela 1 - Codificação das variáveis adotadas no processo de adsorção

\begin{tabular}{|c|c|c|c|c|c|}
\hline \multirow{2}{*}{ Variáveis } & \multicolumn{5}{|c|}{ Níveis } \\
\cline { 2 - 6 } & $-1,147$ & -1 & 0 & +1 & $+1,147$ \\
\hline \hline Massa de adsorvente [g] & 5 & 2,8 & 20 & 35 & 37,2 \\
\hline Tempo de contato [min] & 2 & 1,56 & 5 & 8 & 8,44 \\
\hline
\end{tabular}

Como variável resposta foi adotada a remoção de corante (\%) (Equação 1) a qual foi determinada por meio da avaliação da concentração de azul de metileno residual na solução obtida após a adsorção e filtração (curva de calibração).

$$
\% \text { Remoção }=100 x\left(1-\frac{C_{\text {final }}}{C_{\text {inicial }}}\right)
$$

Para o tratamento estatístico dos dados, empregou-se o Software Statistica versão 7, obtendo-se desse modo o diagrama de Pareto e as superfícies de resposta.

\section{RESULTADOS E DISCUSSÃO}

\subsection{Ponto de carga zero}

A Figura 1 apresenta o ponto de carga zero obtido para a casca do pequi submetida ao pré-tratamento ácido/base. O valor do ponto de carga zero obtido foi de 4,33. Segundo Deolin (2013) para soluções aquosas com $p$ Hs superiores ao do ponto de carga zero, a superfície é carregada negativamente e, adsorve, preferencialmente, cátions. Ressalta-se que o azul de metileno é um corante catiônico, sendo assim, sua adsorção pode ser favorecida por $p \mathrm{Hs}$ superiores a 4,33. Dias (2013) obteve ponto de carga zero para carvão ativado de pequi 8,02; valor superior ao obtido por essa pesquisa. Entretanto, ressalta-se que a casca utilizada por Dias (2103) foi submetida à calcinação, ou seja, contém elevados teores de cinzas do carvão.

Figura 1- Determinação do ponto de carga zero para a casca de pequi pré-tratada com ácido/base

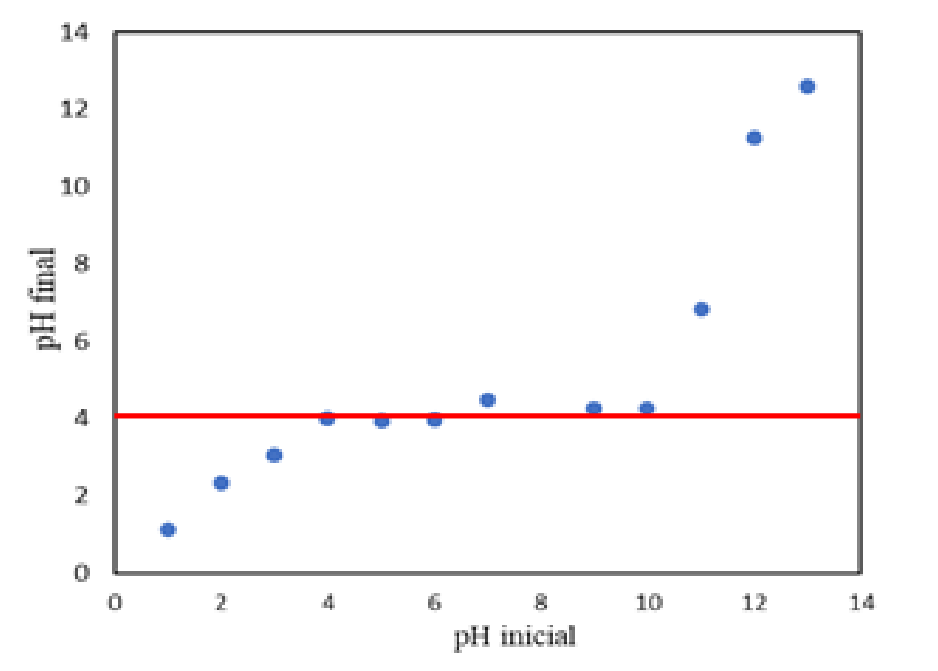




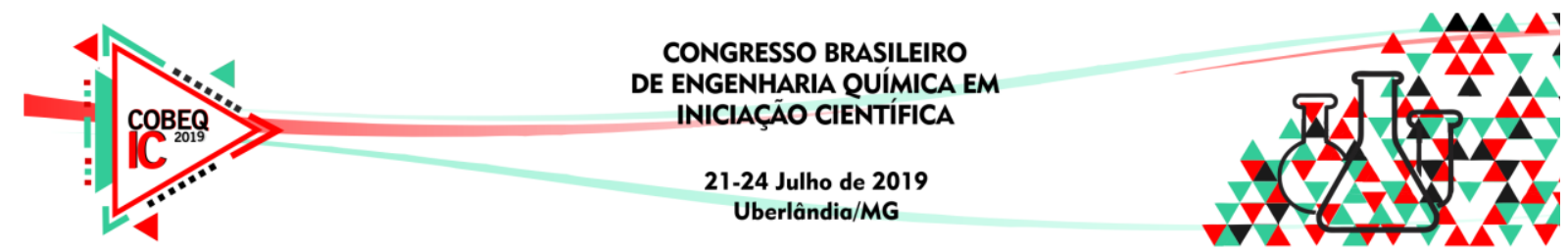

\subsection{A adsorção}

Os ensaios de adsorção foram realizados na condição experimental de $p \mathrm{H}$ 6,6 por favorecer a adsorção do azul de metileno e atender aos quesitos da legislação ambiental.Os resultados obtidos para a remoção do corante azul de metileno, por meio da adsorção com casca de pequi seguindo o delineamento experimental para otimização do tempo de contato e da massa de adsorvente, estão expostos na Tabela 2. Observa-se que a maior taxa de remoção $(73,18 \%)$ ocorreu nas condições de $2 \mathrm{~g}$ de adsorvente e tempo de contato de $35 \mathrm{~min}$.

Tabela 2- Remoção do corante azul de metileno na adsorção usando casca de pequi

\begin{tabular}{|c|c|c|}
\hline Massa adsorvente $(\mathrm{g})$ & Tempo (min) & Remoção (\%) \\
\hline \hline 2,00 & 5,0 & $64,15 \pm 1,80$ \\
\hline 8,00 & 5,0 & $60,66 \pm 1,00$ \\
\hline 2,00 & 35,0 & $73,18 \pm 0,17$ \\
\hline 8,00 & 35,0 & $47,08 \pm 0,13$ \\
\hline 5,00 & 2,80 & $62,09 \pm 2,91$ \\
\hline 5,00 & 37,2 & $63,96 \pm 2,15$ \\
\hline 1,56 & 20,0 & $69,22 \pm 0,43$ \\
\hline 8,44 & 20,0 & $55,27 \pm 0,46$ \\
\hline 5,00 & 20,0 & $68,30 \pm 0,29$ \\
\hline 5,00 & 20,0 & $66,82 \pm 1,17$ \\
\hline 5,00 & 20,0 & $67,80 \pm 1,25$ \\
\hline
\end{tabular}

Patias et al. (2015) em seu estudo de adsorção do corante azul de metileno com carvão ativado proveniente de casca de pequi, obteve remoção de $68 \%$, resultados inferiores ao desta pesquisa. Já Olivério et al. (2015) obtiveram 30\% de remoção do corante vermelho de fenol, usando a casca de pequi tratada e na otimização do processo o referido autor também obteve melhores resultados para as condições de menores massas.

Após tratamento estatístico dos dados verifica-se pelo Diagrama de Pareto (Figura 2), nos níveis estudados, que apenas a variável tempo (linear) não exerceu efeito significativo sobre a remoção do corante. Destaca-se que os valores negativos no diagrama de Pareto para os parâmetros analisados indicam uma relação inversa, ou seja, acréscimos da massa de biossorvente e do tempo de contato acarretam reduções na remoção do corante azul de metileno. A redução da remoção de corante associada ao aumento da massa pode indicar agregação das partículas durante a agitação, o que acarretou em menor área disponível de sítios para adsorção (REIS; LIMA; SAMPAIO, 2015).

Após desprezar a variável estatisticamente não significativa obteve-se a equação, ou seja, o modelo empírico capaz de predizer a remoção do azul de metileno pela casca de pequi, dentro do intervalo de estudo (Equação 2).

Remoção $(\%)=67,4021-13,7551 * X_{1}-7,0626 * X_{1}{ }^{2}-5,8771 * X_{2}^{2}-11,34042 * X_{1} X_{2}$

em que $\mathrm{X}_{1}$ é a massa de adsorvente e $\mathrm{X}_{2} \mathrm{o}$ tempo de contato

A superfície de resposta e a curva de contorno gerada pela equação são explicitadas pela Figura3, nas quais é possível visualizar os efeitos das variáveis frente à remoção. 


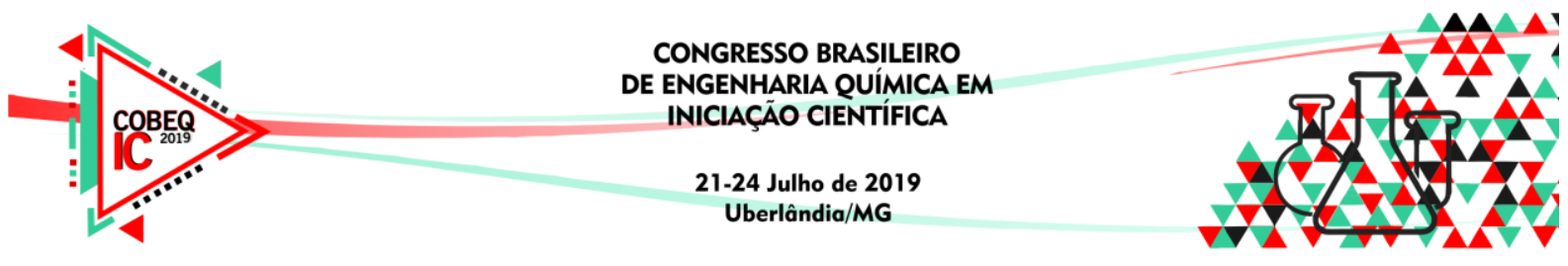

Figura 2 - Diagrama de Pareto obtido para a remoção de azul de metileno pelas cascas de pequi

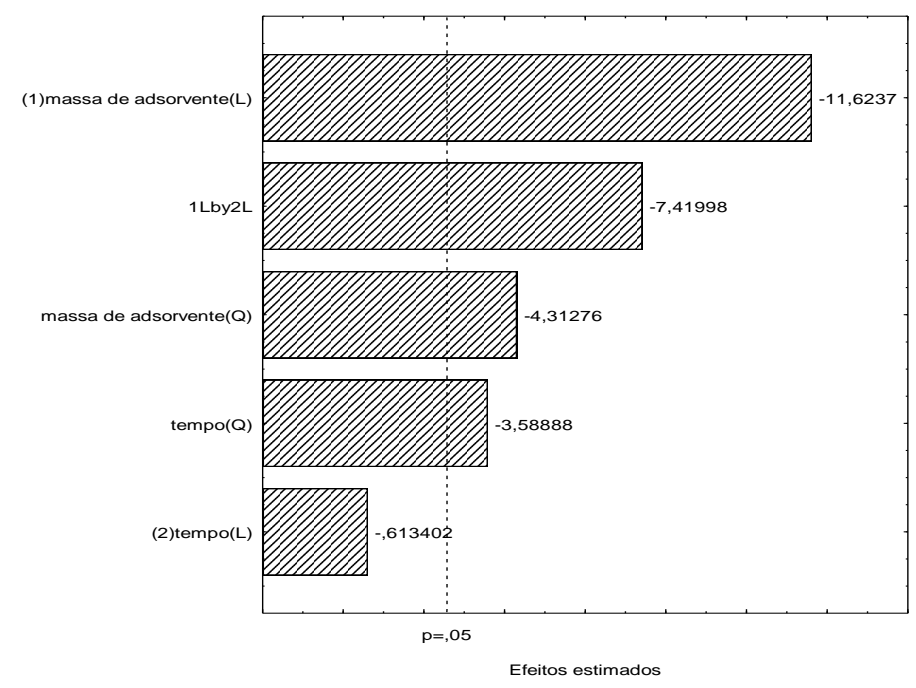

Figura 3 - Superfície de resposta (a) e curvas de contorno (b) obtidas para a remoção de azul de metileno utilizando cascas de pequi como adsorvente

(a)

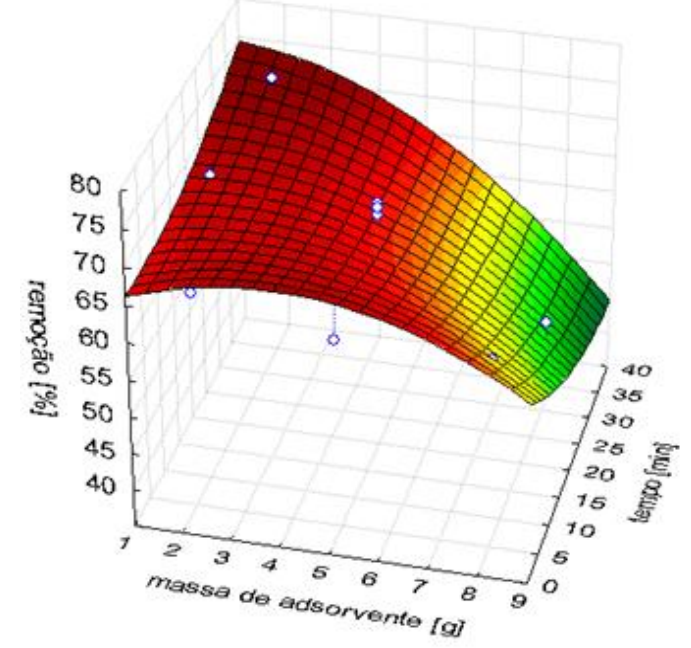

(b)

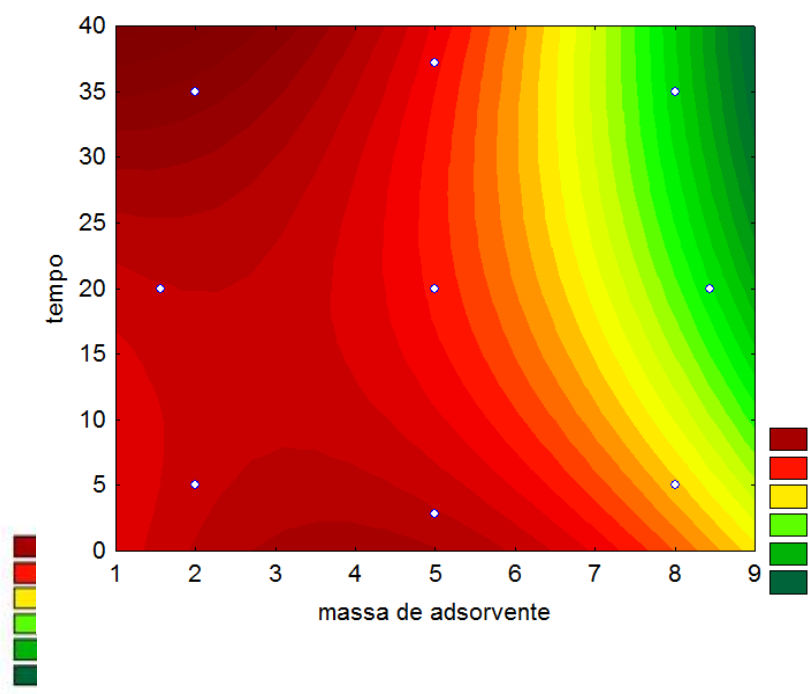

Fica evidenciado pelos gráficos que condições elevadas de tempo de contato (acima de $30 \mathrm{~min}$ ) associadas a baixas massas cascas de pequi (menor que $4 \mathrm{~g}$ ) contribuem para a adsorção do azul de metileno. Entretanto, condições experimentais de $4 \mathrm{~g}$ de adsorvente e tempo de contato de 2 min também favorecem a adsorção. Ressalta-se que a condição de elevada massa ( $9 \mathrm{~g}$ ) e elevado tempo de contato (acima de $25 \mathrm{~min}$ ) acarretaram reduções significativas sobre a remoção do azul de metileno. 


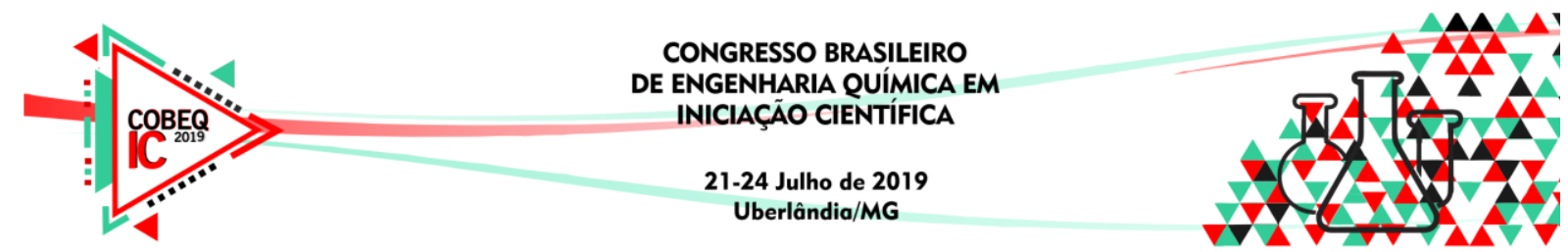

\section{CONCLUSÃO}

Através da determinação do ponto de carga zero evidencia-se que valores de $p \mathrm{H}$ superiores a 4,33 favorecem a adsorção do corante azul de metileno pela casca de pequi. A partir do planejamento experimental foi possível obter as melhores condições operacionais de tempo e massa de adsorvente. Os resultados apontam que a casca de pequi pode ser considerada um bom adsorvente alternativo de baixo custo, devido à eficiência de remoção e à sua disponibilidade na natureza, com potencial para tratamento de soluções contaminadas com corante de azul de metileno.

\section{REFERÊNCIAS}

AMORIM, Dayane de Jesus. Caracterização e avaliação da potencialidade das cascas trituradas de pequi (caryocar brasiliense camb.) na adsorção de íons Pb(II) em águas. 2015, $79 \mathrm{f}$. Dissertação (Mestrado) - Curso de Recursos Naturais do Cerrado, Universidade Estadual de Goiás, Anápolis, 2015.

DEOLIN, Mara Helen da Silva. Encontro Internacional de Produção Científica, 8., 2013, Maringá. Obtenção do ponto de carga zero de materiais adsorventes. Maringá, Paraná: Cesumar, 2013. 4 p.

LUNARDI, Layane Martins. Remoção de corantes têxteis por adsorção com pó de serragem de pinus sp. 2014. 54 f. TCC (Graduação) - Curso de Engenharia Civil, Departamento de Engenharia Civil, Universidade Tecnológica Federal do Paraná, Campo Mourão, 2014.

NASCIMENTO, Ronaldo Ferreira do et al. Adsorção: aspectos teóricos e aplicações ambientais. Fortaleza: Imprensa Universitária, 2014. 256 p.

OLIVÉRIO, Guilherme Nunes et al. A utilização de casca de pequi como adsorvente do corante vermelho de fenol em meio aquoso. In: Jornada de Iniciação Científica e Extensão, 6., 2015, Araguatins -TO: 2015. p. 1 - 8.

PATIAS, Samira Gabrielle Oliveira et al. Obtenção de carvão adsorvente oriundo da casca de pequi (Caryocar brasiliense) e sua aplicação no tratamento de efluentes da indústria têxtil através do processo de adsorção. Revista Eletrônica em Gestão, Educação e Tecnologia Ambiental, Santa Maria, v. 19, n. 2, p.1482-1492, maio/set. 2015..

ROSAS, Veronica Heloisa et al. Avaliação da técnica de biossorção de corante utilizando a biomassa de coco verde: uma alternativa sustentável para o tratamento de efluentes industriais. In: Encontro Nacional de Engenharia de Produção, 36, 2016, João Pessoa - Pb. Anais. João Pessoa $\mathrm{Pb}$ : ABEPRO, 2016. p. 1 - 9.

SILVA, Lívia Fernanda. Utilização do pó de serragem como adsorvente alternativo na remoção de verde de malaquita. 2014, 36 f. TCC (Graduação) - Curso de Engenharia Civil, Universidade Tecnológica Federal do Paraná, Campo Mourão, 2014.

SOARES JÚNIOR, Manoel Soares et al. Qualidade de biscoitos formulados com diferentes teores de farinha de casca de pequi. Pesquisa Agropecuária Tropical, Goiânia/GO, v. 39, n. 2, p. 98-104, maio 2009.

REIS, Glaydson Simões dos; LIMA, Eder Claudio; SAMPAIO, Carlos Hoffman. Produção de carvão ativado a partir de lodo de esgoto doméstico e sua aplicação na adsorção do corante preto remazol 5 em solução aquosa. E-xacta, [s.1.], v. 8, n. 2, p.15-23, 30 nov. 2015. 